\title{
Chemokines: role in inflammation and immune surveillance
}

\author{
B Moser, K Willimann
}

Ann Rheum Dis 2004;63(Suppl II):ii84-ii89. doi: 10.1136/ard.2004.028316

\begin{abstract}
Chemotactic migration of leucocytes largely depends on adhesive interaction with the substratum and recognition of a chemoattractant gradient. Both aspects, cell adhesion and chemotaxis, are regulated by members of the family of chemotactic cytokines (chemokines) comprising structurally related and secreted proteins of 67-127 amino acids in length. Breakdown in the control of leucocyte mobilisation contributes to chronic inflammatory diseases and, hence, interference with chemokine function is a promising approach for the development of novel anti-inflammatory medication. Chemokines target all types of leucocyte, including haematopoietic precursors, mature leucocytes of the innate immune system as well as naive, memory, and effector lymphocytes. The combinatorial diversity in responsiveness to chemokines ensures proper tissue distribution of distinct leucocyte subsets under normal and inflammatory/ pathological conditions. Here, we discuss recent views on the role of chemokines in controlling tissue localisation of human memory T cells under steady state (non-inflamed) conditions. Emphasis is placed on a concept describing distinct subsets of memory $\mathrm{T}$ cells according to their primary residence in peripheral blood, secondary lymphoid tissues, or peripheral (extralymphoid) tissues.
\end{abstract}

T he large majority of approximately 50 human chemokines fall into the group of either CXC or CC chemokines. ${ }^{12}$ In addition, there are two C chemokines, Ltn- $\alpha /$ XCL1 and Ltn- $\beta /$ XCL2, in which two out of the four conserved Cys residues are missing, and a single CX3C chemokine, called fractalkine/CX3CL1, with three amino acids separating the two $\mathrm{NH}_{2}$ terminal Cys residues. Two nomenclature systems are used in the current literature, the traditional abbreviations dating back to the time of chemokine discovery, such as interleukin (IL)-8 and monocyte chemoattractant protein (MCP)-1, and a systematic nomenclature that combines structural motifs (CXC, CC, $\mathrm{XC}, \mathrm{CX} 3 \mathrm{C}$ ) with $\mathrm{L}$ for ligand and the number of the respective gene (http://cytokine.medic.kumamoto-u.ac.jp gives access to recent updates $\left.{ }^{3}\right){ }^{4-6}$ Chemokine receptors are designated according to the type of chemokine(s) they bind (CXC, CC, $\mathrm{XC}, \mathrm{CX} 3 \mathrm{C})$, followed by $\mathrm{R}$ for receptor and a number indicating the order of discovery. In this article we have combined the "common" name with the systematic nomenclature at the first instance a particular chemokine is mentioned and then used the systematic name in the remainder of the text.

Chemokine receptors belong to the large family of seven transmembrane domain receptors which couple to heterotrimeric GTP-binding proteins (G-proteins) (fig 1).4578 Experiments with Bordetella pertussis toxin have indicated that these receptors typically require $\mathrm{G}$-proteins of the $\mathrm{G}_{\mathrm{i}}$-type for signal transduction. ${ }^{459}$ Currently, the human system is composed of 6 CXCRs, 10 CCRs, I CX3CR, and I XCR. The most recent chemokine binding protein is a structural variant of CXCR3, termed CXCR3-B, which binds the classical CXCR3 ligands: monokine induced by interferon $\gamma$ (Mig)/CXCL9, interferon $\alpha$ inducible protein 10 (IP10)/CXCL10, and interferon inducible $\mathrm{T}$ cell alpha chemoattractant (I-TAC)/ CXCL11 as well as platelet factor $4 /$ CXCL4 ${ }^{10}$ CXCR3-B has been shown to inhibit endothelial cell growth in a B. pertussis toxin-insensitive manner, but it failed to mediate chemotaxis, indicating a role that is distinct from the prototype chemoattractant function. There are considerable species differences, as demonstrated by the presence of a single IL-8 receptor in rabbits and mice but not in rats or humans, and the lack of an IL-8 homologue in mice but not in rabbits or humans.

Downstream second messengers of G-protein signalling include phospholipase C $\beta$ (PLC $\beta$ ) isoforms, Ser/Thr kinases, phosphatidylinositol 3-kinase- $\gamma(\mathrm{PI} 3 \mathrm{~K} \gamma)$ and c-Src related non-receptor tyrosine kinases. ${ }^{78}$ Cellular responses to chemokines are typically rapid in onset and transient in duration. The negative control mechanism elicited during chemokine receptor signalling is termed cellular desensitisation and is by itself also transient-that is, cells regain responsiveness to a given chemokine after a short period of culturing in chemokine depleted medium. Homologous desensitisation is mediated by G-protein coupled receptor kinases (GRKs), which block further signal transduction by phosphorylating Ser/The residues in the intracellular $\mathrm{C}$ terminal domains of ligand occupied chemokine receptors and other G-protein coupled receptors (GPCRs). Uncoupling from G-proteins is also observed in a process called heterologous desensitisation that involves phosphorylation of ligand free (non-engaged) chemokine receptors or other GPCRs by alternative protein kinases. GRK mediated receptor phosphorylation initiates $\beta$-arrestin binding, which leads to sequestration or clustering in specialised clathrin-rich membrane microdomains and endocytic uptake of chemokine-receptor complexes. Rapid internalisation allows the continuous redistribution of chemokine receptors on leucocytes for maintaining polarised chemokine sensing and directed cell migration along a chemokine gradient. Not all chemokine binding proteins induce cell migration, as exemplified by CXCR3-B (see above; reference 10), the "decoy" chemokine receptors D6," and the Duffy antigen related chemokine receptor (DARC). ${ }^{12}$ Furthermore, the signal transduction machinery of certain chemokine receptors can become uncoupled, as documented by the IL-10 mediated silencing of chemokine receptors in monocytes and dendritic cells (DCs). ${ }^{13}$

Numerous chemokine receptors are highly promiscuous in their chemokine selectivity, and vice versa, numerous chemokines bind to more than one receptor. ${ }^{4-6} 14$ These redundant chemokine systems are most frequently associated with inflammation, which is in contrast with several monogamous chemokine systems with function in homoeostatic

Abbreviations: DC, dendritic cell; GPCR, G-protein coupled receptor; G-proteins, GTP-binding proteins; GRK, G-protein coupled receptor kinase; IL, interleukin; LN, lymph node; PP, Peyer's patch; Th, T helper 

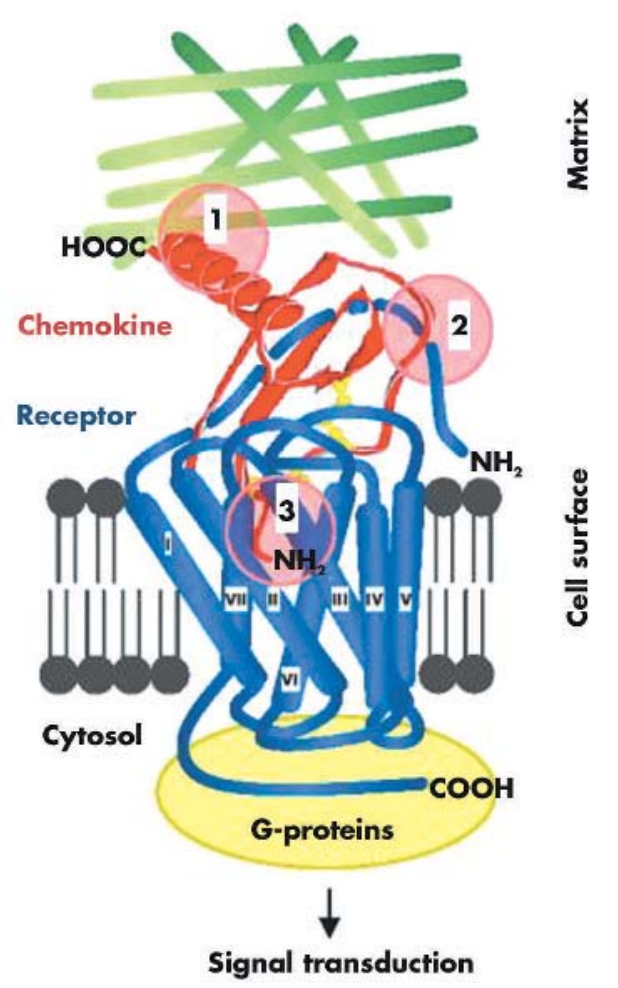

号

Figure 1 Chemokine-receptor interactions. Chemokine receptors are embedded into the membrane by seven transmembrane domains. The $\mathrm{NH}_{2}$-terminus and three extracellular loop regions are involved in chemokine binding, and the $\mathrm{COOH}$-terminus and three intracellular loop regions participate in G-protein mediated signal transduction. The three sites in chemokines that are essential for function include (1) the matrix fixation site in the $\mathrm{COOH}$ terminal $\alpha$-helix or core structure, (2) the $\mathrm{N}$ loop region enabling initial receptor contact, and (3) the $\mathrm{NH}_{2}$-terminus, which interacts with the chemokine binding pocket formed by the transmembrane regions of the chemokine receptor.

leucocyte development and migration processes. Recent reports provide strong evidence for the existence of natural chemokines with combinatorial agonistic-antagonistic activity, underscoring their importance as controllers of leucocyte navigation. ${ }^{15}$ CXCL9, CXCL10, and CXCL11, the agonists for CXCR3, are antagonists for CCR3, the receptor for eotaxin/ CCL11 and several other CC chemokines. ${ }^{16}$ Since CXCR3 and CCR3 are differentially expressed in T helper (Th) 1 and Th 2 cells, these findings suggest that CXCL9, CXCL10, and CXCL11, in addition to attracting CXCR3 bearing cells, have the capacity to block migration of CCR3+ cells, thereby contributing to Thl-type immune response polarisation. Other natural chemokines with antagonistic activities are CCL11 and eotaxin-3/CCL26, which attract eosinophils, basophiles, and Th 2 lymphocytes via CCR3, while blocking CCR2+ cells and (in case of CCL26) CCR5+ cells. ${ }^{17-19}$ Also, MCP-3/CCL7, a potent agonist for CCR1, CCR2, and CCR3 has been shown to block CCR5+ cells. ${ }^{20}$ Together, the combination of stimulatory and inhibitory properties represents another level of control that influences chemokine receptor function and, thus, ongoing immune processes.

\section{MULTIPLE STEP LEUCOCYTE MIGRATION CONTROL}

Chemoattractant activity and the "four Cys residue" fingerprint arrangement prompted the term chemokines to designate this novel group of chemotactic cytokines. ${ }^{21}$ In addition to the $\mathrm{CXC}, \mathrm{CC}, \mathrm{XC}$, and $\mathrm{CX} 3 \mathrm{C}$ classification, chemokines are also grouped into functional subsets. ${ }^{7}{ }^{122}$ Inflammatory chemokines control the recruitment of effector

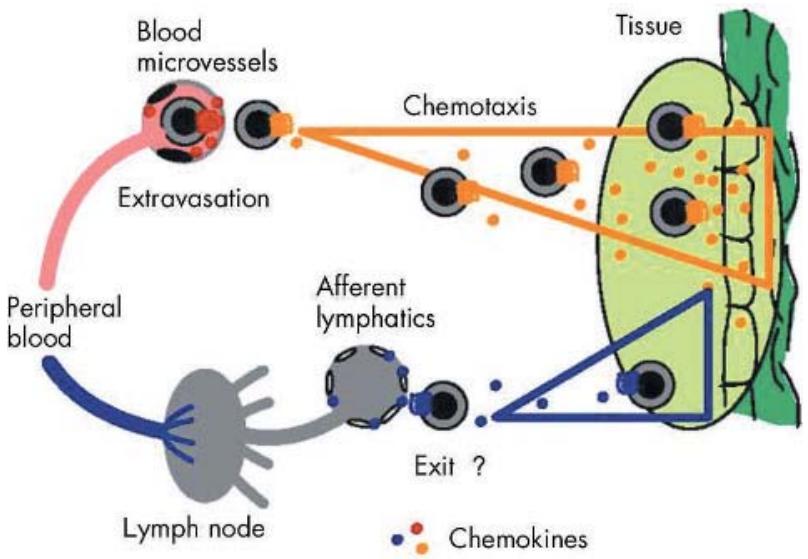

Figure 2 Recruitment, localisation, and tissue exit of circulating leucocytes. Tissue localisation of leucocytes involves two distinct and sequential processes, termed extravasation and chemotaxis. During extravasation, blood leucocytes interact with adhesion molecules on the luminal side of blood vessels and, upon chemokine receptor triggering, become firmly attached and transmigrate through the epithelial barrier. Subsequent chemotaxis guides the perivascular leucocytes to the cellular source(s) of chemokines, which enables cellular colocalisation and subsequent execution of leucocyte function. Eventually, leucocytes exit the tissue via afferent lymphatic vessels to reach draining lymph nodes $(\mathrm{LNs})$ and peripheral blood.

leucocytes in infection, inflammation, tissue injury, and tumours. Many of the inflammatory chemokines have broad target cell selectivity and act on cells of the innate as well as the adaptive immune system. Homoeostatic chemokines, in contrast, navigate leucocytes during haematopoiesis in the bone marrow and thymus, during initiation of adaptive immune responses in the spleen and lymph nodes, and in immune surveillance of healthy peripheral tissues. Recent findings indicate that several chemokines cannot be assigned unambiguously to either of the two functional categories and, therefore, may be referred to as "dual function" chemokines. ${ }^{14}$

Recruitment of circulating leucocytes to sites of pathogen entry or inflammation involves two separate migration processes, termed extravasation and chemotaxis (fig 2). Adhesion to the luminal side of blood vessels, transendothelial migration, and subsequent chemotaxis of leucocytes are highly complex processes, which are controlled by "outsidein" and "inside-out" signalling events during cellular interactions of blood leucocytes with vascular chemokines and adhesion ligands. Triggering of chemokine receptors in leucocytes by endothelia associated chemokines is a requirement for extravasation and induces a rapid increase in integrin affinity/avidity, which results in firm but transient leucocyte adhesion. ${ }^{23}$ Subsequently, the adherent leucocytes move across the endothelial cell layer and the underlying basement membrane and are released into the tissue. ${ }^{24}$ Of note, only those types of leucocyte are able to transmigrate at a given vascular site, which are capable of responding to the chemokines present on the local endothelium. In other words, chemokines and their receptors largely determine the selectivity in leucocyte extravasation. ${ }^{4} 571422$

After crossing the endothelial barrier, perivascular leucocytes will chemotax in response to a chemokine gradient, allowing more precise localisation of the leucocytes within the tissue (see fig 2). Importantly, chemokines forming a gradient in the tissue do not need to be identical to those controlling attachment of leucocytes to microvascular endothelial cells. As mentioned above, chemokine binding quickly leads to neutralisation and endocytosis of engaged receptors, thereby allowing continuous redistribution of 


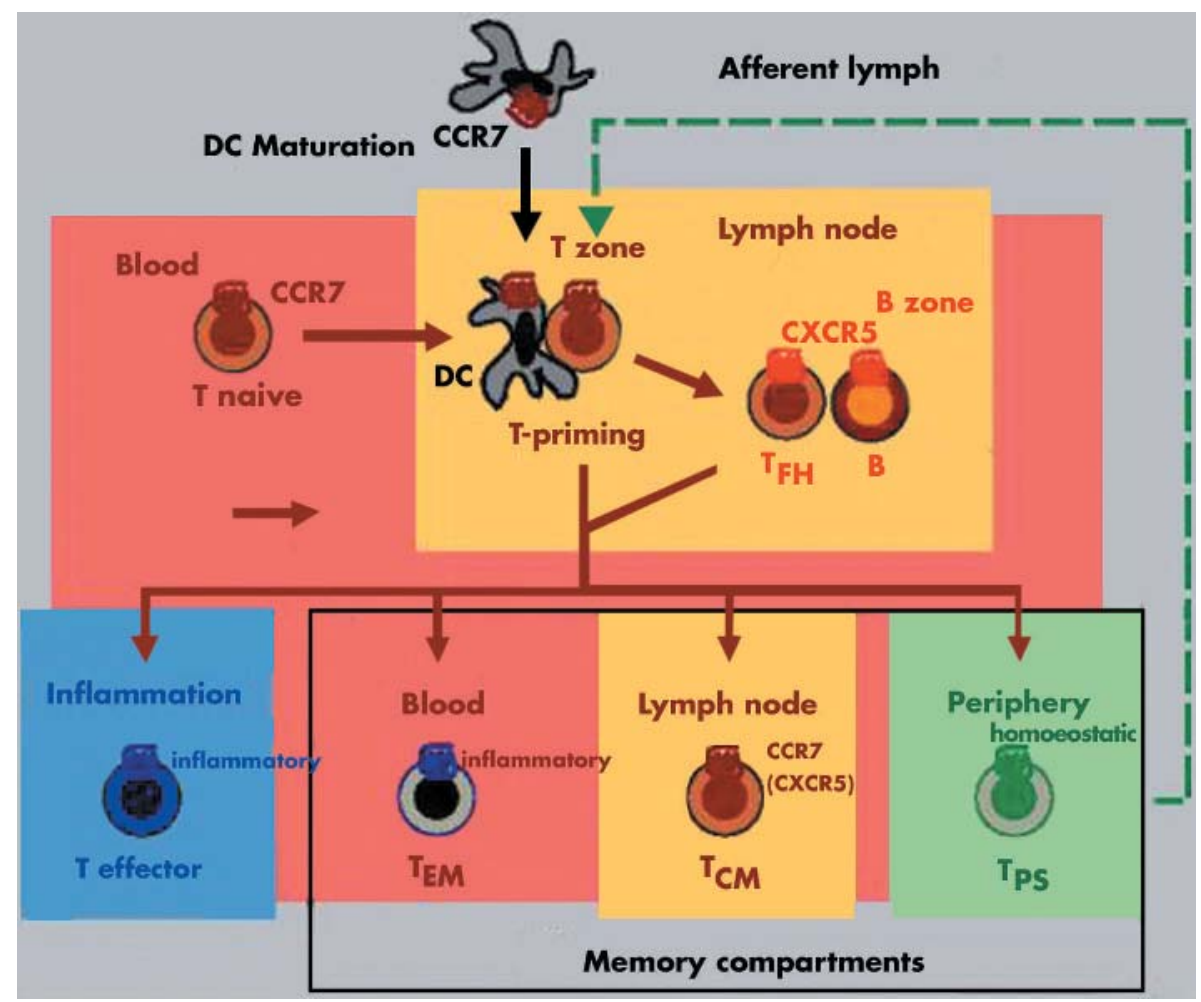

Figure 3 Chemokine receptors define distinct migratory T cell subsets. Naive T cells develop into effector and memory T cells accompanied by major changes in chemokine receptor expression and responsiveness to chemokines. Effector T cells are short lived and efficiently home to sites of inflammation. Memory T cells, in contrast, are long lived and are classified here according to their principal site of residence. TEM cells mainly reside in peripheral blood and are ready to respond to inflammatory chemokines at sites of immune response. Resting TEM cells lack CCR7 and are excluded from lymph nodes (LNs) and Peyer's patches (PPs). T TM cells express CCR7 and adhesion molecules for homing to T zones of secondary lymphoid tissues. Their principal function is the screening of $L N s$ and PPs for the presence of recall antigens presented by local dendritic cells (DCs). Finally, $T_{P S}$ cells primarily reside in healthy (extralymphoid) peripheral tissues whereas they are rare in peripheral blood, LNs, and PPs. Their primary function is immune surveillance at sites of previous antigen encounter. B, B cells; T naive; naive T cells; T effector, effector $T_{\text {cells, }} \mathrm{T}_{C M}$, central memory $\mathrm{T}_{\mathrm{c}}$ cells; $\mathrm{T}_{\mathrm{EM}}$, effector memory $\mathrm{T}$ cells; $\mathrm{T}_{\mathrm{FH}}$, follicular B helper T cells; $\mathrm{T}_{\mathrm{PS}}$, peripheral immune surveillance $\mathrm{T}$ cells; inflammatory and homoeostatic, receptors for inflammatory and homoeostatic chemokines, respectively.

chemokine receptors and de novo chemokine sensing. At the site of chemokine production where chemokine concentrations are highest, homologous desensitisation may impede leucocyte migration and, in the presence of alternative chemokine gradients, may allow their further relocation. ${ }^{25}$

Some $\mathrm{T}$ cells and maturating (inflammatory) DCs exit the tissue site to reach secondary lymphatic tissues and blood (see fig 2). For instance, naive T cells and B cells within LNs and Peyer's patches (PPs) that remain uninvolved in local immune processes return to peripheral blood by means of efferent lymphatic channels. Similarly, immune surveillance $\mathrm{T}$ cells (see below) may also exit healthy epithelial tissues via afferent lymphatic channels, local LNs, and the thoracic duct to reach blood circulation. The molecules controlling this reverse (abluminal to luminal) transmigration across the lymphatic endothelium are poorly defined but chemokines and adhesion molecules may also be involved. Recent data indicate a role for sphingosine-1-phosphate (S1P) receptors in the exit of lymphocytes from the thymus and LN, but the underlying mechanisms are not yet understood. ${ }^{26}$ Similarly, CD38 was shown to affect DC traffic into and out of tissues by modulating chemokine receptor function, ${ }^{27}$ and blockage of the multiple drug resistance protein (MDR)-1 prevented the exit of skin DCs. ${ }^{28}$ Desensitisation of chemokine receptors by the high local concentration of chemokines in LNs may also play an important role in releasing lymphocytes from these sites. With regard to afferent lymphatic vessels, expression of secondary lymphoid tissue chemokine (SLC)/ CCL2 1 was shown to be essential for guiding mature, CCR7 expressing DCs to local LNs. ${ }^{29}$ However, it is not known at all whether naive, effector, or immune surveillance $\mathrm{T}$ cells use a similar mechanism for tissue exit. Finally, the chemokine binding protein D6 marks afferent lymphatic vessels, suggesting involvement in lymphatic leucocyte traffic. ${ }^{11}$

\section{CHEMOKINES DEFINE "MIGRATORY" T CELL SUBSETS}

Two types of Ag-experienced $\mathrm{T}$ cell subset are produced during adaptive immune responses: large numbers of short lived effector $\mathrm{T}$ cells and a minor fraction of long lived memory T cells (fig 3). ${ }^{30-32}$ Effector T cells are equipped with receptors for inflammatory chemokines and adhesion molecules that are greatly upregulated during inflammation and, thus, these cells efficiently home to sites of pathogen entry and disease. As an example, fig 4 shows a list of chemokines that were found to be present in the synovial fluid and inflamed tissue of joints with rheumatoid arthritis, and similar situations are found in other acute and chronic inflammatory diseases. Clearly, no known chemokine system is singularly responsible for recruitment of effector cells to inflammatory sites. Also, during the evolution of the disease the composition of inflammatory chemokines induced at these locations may change and thus may affect the composition of the recruited inflammatory cells. Inflammatory responses at early stages are often dominated by neutrophils and monocyte/macrophages, which is reflected by the predominance of chemokines targeting cells of the innate immune system. During later stages, additional 


\section{A}

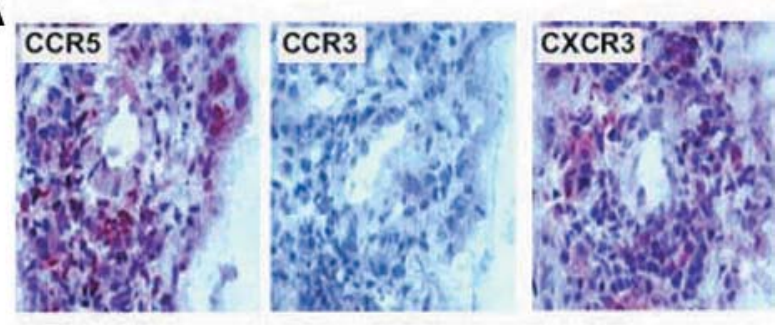

B

\begin{tabular}{|c|c|c|}
\hline CHEMOKINES & RECEPTORS & TARGETS \\
\hline $\begin{array}{l}\text { GRO } \alpha-\gamma / C X C L 1-3 \\
\text { ENA78/CXCL5 } \\
\text { GCP-2/CXCL6 } \\
\text { IL-8/CXCL8 }\end{array}$ & $\begin{array}{l}\text { CXCR1 } \\
\text { CXCR2 }\end{array}$ & Neutrophils \\
\hline $\begin{array}{l}\text { Mig/CXCL29 } \\
\text { IP10/CXCL10 } \\
\text { CXCL16 } \\
\text { MCP-1/CCL2 } \\
\text { MCP-2/CCL8 } \\
\text { MIP-1 } \alpha, \text { /1/CCL3,4 } \\
\text { RANTES/CCL5 } \\
\text { LARC/CCL20 }\end{array}$ & $\begin{array}{l}\text { CXCR3 } \\
\text { CXCR6 } \\
\text { CCR1 } \\
\text { CCR2 } \\
\text { CCR5 } \\
\text { CCR6 }\end{array}$ & $\begin{array}{l}\text { Monocytes } \\
\text { Macrophages } \\
\text { T Cells }\end{array}$ \\
\hline $\begin{array}{l}\text { BCA-1/CXCL13 } \\
\text { ELC/CCL19 } \\
\text { SLC/CCL21 }\end{array}$ & $\begin{array}{l}\text { CXCR5 } \\
\text { CCR7 }\end{array}$ & $\begin{array}{l}\text { "Follicular" } \\
\mathrm{T} \text { and B Cells }\end{array}$ \\
\hline SDF-1/CXCL12 & CXCR4 & Multiple \\
\hline
\end{tabular}

Figure 4 Complex composition of chemokines and chemokine receptors in rheumatoid arthritis. (A) As an example, inflammatory cells in the affected synovial tissue express Th 1 typical chemokine receptors CXCR3 and CCR5 but not the CCR3, which is more prominent on Th 2 cells. (B) A multitude of chemokines were detected in the synovial fluid and inflamed synovial tissue. The chemokines are listed according to their receptor selectivity and target cells. Of note, the condition of rheumatoid arthritis leads to the generation of all chemokines necessary for recruitment of the full complement of effector cells. BCA, B cell attracting chemokine; ELC, EBI-1-ligand chemokine; ENA, epithelial cell derived neutrophil activating protein; GCP, granulocyte chemotactic protein; GRO, growth related oncogene; IP, interferon $\alpha$ inducible protein; LARC, liver and activation regulated chemokine; MCP, monocyte chemoattractant protein; Mig, monokine induced by interferon $\gamma ;$ MIP, macrophage inflammatory protein; RANTES, regulated on activation, normal T cell expressed and secreted; SDF-1, stromal cell derived factor 1; SLC, secondary lymphoid tissue chemokine.

chemokines are responsible for the recruitment of effector $\mathrm{T}$ cells, and in autoimmune diseases, such as rheumatoid arthritis, the steady influx of macrophages and $\mathrm{T}$ and $\mathrm{B}$ cells is maintained by continuous production of corresponding chemokines. The multitude of inflammatory disease associated chemokines is mirrored by the profile of chemokine receptors present on cells within the inflammatory infiltrates (see fig 4). ${ }^{14}$ It is interesting to note that several homoeostatic chemokines, with primary function in secondary lymphoid tissues (B cell attracting chemokine (BCA)-1/CXCL13, EBI-1ligand chemokine (ELC)/CCL19 and CCL21) have also been detected in rheumatoid arthritis and several other chronic inflammatory diseases. ${ }^{33}$ These chemokines are frequently associated with extranodal follicular structures resembling B cell follicles or even LNs, which is in agreement with their role in LN neogenesis. ${ }^{14}{ }^{34}$ In addition, these chemokines orchestrate cellular contacts between T cells, B cells, and DCs for the generation of effector cells and, thus, may contribute to disease chronicity. However, currently no direct correlation has been found between the presence of such lymphoid structures and the severity of local inflammation.

Development of low molecular weight compounds for blocking chemokine receptors has become a major goal of the pharmaceutical industry. ${ }^{35} 36$ Obvious targets are receptors that control leucocyte recruitment to inflammatory sites, such as in rheumatoid arthritis, or those with human immunodeficiency virus (HIV)-1 coreceptor function, and several mostly polycyclic lead compounds are currently being examined. ${ }^{35}$ Thus far, research has focused on blocking single chemokine receptors. However, given the apparent redundancy of the inflammatory chemokine system (for example see fig 4), compounds with multiple receptor selectivity need to be considered as more efficient anti-inflammatory agents.

In contrast to naive $\mathrm{T}$ cells, memory $\mathrm{T}$ cells are believed to provide rapid and superior protection against pathogens they have encountered during previous immune responses. ${ }^{30-32}$ Classically, memory $\mathrm{T}$ cells are further subdivided into functional subgroups: Th cells are mostly major histocompatibility complex (MHC) class II restricted and produce type 1 interferon $\gamma$ or type 2 (IL-4, IL-5, IL-13) cytokines whereas subsets of regulatory $\mathrm{T}$ cells inhibit $\mathrm{T}$ helper responses possibly by cell to cell contact and/or IL-10/TGF $\beta$ secretion. Cytolytic T cells are mostly MHC class I restricted and kill target cells by perforin and granzyme dependent processes. Here we wish to emphasise an alternative classification of memory $\mathrm{T}$ cells based on their primary residence in distinct body compartments. The three main memory $\mathrm{T}$ cell compartments are peripheral blood, secondary lymphoid tissues (spleen, LNs, PPs), and healthy peripheral (extralymphoid) tissues, and the three subsets of $\mathrm{T}$ cells residing in these locations are termed effector memory $\mathrm{T}\left(\mathrm{T}_{\mathrm{EM}}\right)$ cells, central memory $\mathrm{T}\left(\mathrm{T}_{\mathrm{CM}}\right)$ cells, and peripheral immune surveillance $\mathrm{T}$ $\left(\mathrm{T}_{\mathrm{PS}}\right)$ cells, respectively (see fig 3 ).

$\mathrm{T}_{\mathrm{CM}}$ cells are characterised by a LN-homing address code that includes the expression of the chemokine receptor CCR7 and the adhesion molecules CD62L or $\alpha 4 \beta 7$ for continuous recirculation through the spleen, LNs, and PPs. ${ }^{37}$ A subset of $\mathrm{T}_{\mathrm{CM}}$ cells-follicular $\mathrm{B}$ helper $\mathrm{T}\left(\mathrm{T}_{\mathrm{FH}}\right)$ cell-is abundant in LNs and has the chemokine receptor CXCR5 for efficient homing to the $\mathrm{B}$ cell compartment. ${ }^{38-40}$ In humans, $\mathrm{T}_{\mathrm{CM}}$ cells (and $\mathrm{T}_{\mathrm{FH}}$ cells) have been described as being not differentiated-that is, as being unable to produce inflammatory cytokines or lytic enzymes. This is in contrast with $\mathrm{T}_{\mathrm{EM}}$ cells that immediately initiate effector functions in response to stimulation. Furthermore, due to lack of CCR7 but presence of receptors for inflammatory chemokines, $\mathrm{T}_{\mathrm{EM}}$ cells are excluded from LNs and PPs but, instead, behave as innate cells, such as blood monocytes and granulocytes, which are ready to participate in inflammatory responses. It is important to emphasise that this distinction is not strictthat is, $\mathrm{T}_{\mathrm{EM}}$ cells have the capacity to reacquire CCR7 during restimulation. ${ }^{41}{ }^{42}$ Collectively, the primary residence of $T_{C M}$ cells is in the secondary lymphoid tissues where they participate in responses to recall antigens whereas $T_{E M}$ cells circulate in blood and wait to be recruited to inflammatory sites.

The third class of memory $\mathrm{T}$ cell, called $\mathrm{T}_{\mathrm{PS}}$ cells, are characterised by their preferential localisation in healthy (extralymphoid) peripheral tissues including normal skin and the respiratory and gastrointestinal tracts (see fig 3). Importantly, $\mathrm{T}_{\mathrm{PS}}$ cells-unlike $\mathrm{T}_{\mathrm{CM}}$ and $\mathrm{T}_{\mathrm{EM}}$ cells-have the capacity to respond to chemokines expressed constitutively in healthy peripheral tissues. As a result, they are largely excluded from peripheral blood and secondary lymphoid tissues (spleen, LNs, and PPs). We wish to emphasise that the large majority ( $>95 \%$ ) of $\mathrm{T}$ cells reside outside of peripheral blood at any given moment, indicating that $\mathrm{T}_{\mathrm{PS}}$ cells cannot be studied by examining $\mathrm{T}$ cells isolated from peripheral blood. The rare $\mathrm{T}_{\mathrm{PS}}$ cells found in peripheral blood may be on their way to a distinct peripheral site that produces the homoeostatic chemokine(s) to which they respond. Similar to blood $\mathrm{T}_{\mathrm{CM}}$ cells (and naive $\mathrm{T}$ cells) that constantly 
A

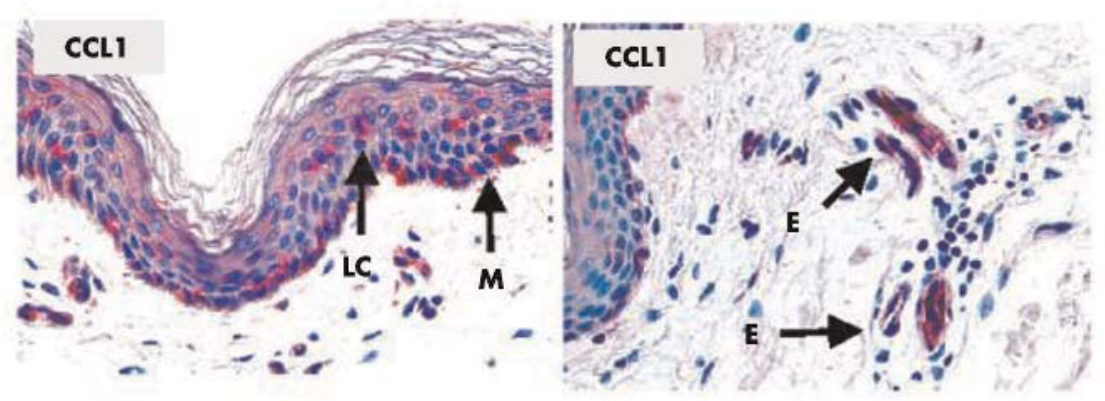

B Freshly isolated human skin T cells
Figure 5 CCR8 marks skin selective immune surveillance $T\left(T_{P S}\right)$ cells. (A) CCL1, the only ligand chemokine for CCR8, is expressed in small amounts by epidermal Langerhans cells (LC) and melanocytes (M) as well as blood vessels in the superficial dermal plexus of normal (non-inflamed) human skin. (B) Summary of phenotypic characteristics of freshly isolated T cells from normal human skin. Please note the abundance of CCR8, which is in striking contrast to the low level of expression of other chemokine receptors that are frequently found on effector/memory T cells in peripheral blood. E, microvascular endothelia.

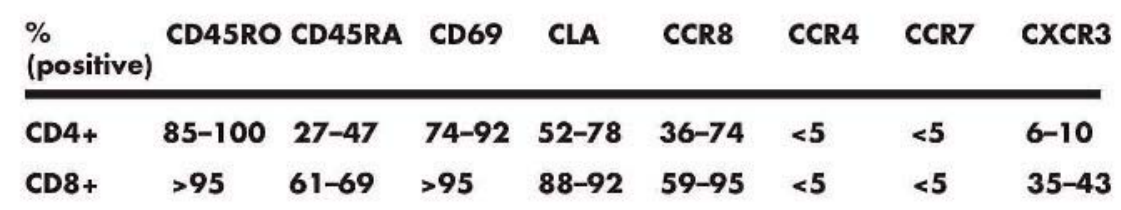

recirculate through secondary lymphoid tissues, $\mathrm{T}_{\mathrm{PS}}$ cells preferentially home to potential sites of pathogen entry (skin, lungs, and gut) for immune surveillance purposes. In contrast to $\mathrm{T}_{\mathrm{CM}}$ cells that need the $\mathrm{LN}$ environment for stimulation, it has been proposed that $\mathrm{T}_{\mathrm{PS}}$ cells fulfil their defensive function directly at the site of pathogen entry.

We know much about the highly sophisticated network of chemokines and adhesion molecules involved in the control of inflammatory cells of both the innate and adaptive immune system, and we have some ideas about the regulatory molecules controlling leucocyte traffic within the spleen and LNs. In contrast, we are still at the very beginning of understanding the molecular basis for maintaining the steady state (inflammation unrelated) traffic of peripheral sentinel cells. Inflammatory chemokines are abundant at inflammatory sites and, thus, are relatively accessible for study. Homoeostatic chemokines, in contrast, are produced in low concentrations and are meant to control constitutive recruitment of $\mathrm{T}_{\mathrm{PS}}$ cells in numbers that are many fold lower than effector cells known to "flood" inflammatory sites. Probably, this may explain the more problematic nature of studying homoeostatic chemokines. Recent findings from our laboratory lend support for the $\mathrm{T}_{\mathrm{PS}}$ cell hypothesis. ${ }^{43}$ In human skin, a minor fraction of (mostly CD8+) cutaneous $\mathrm{T}$ cells is found in the epidermis, whereas $90 \%$ of total cutaneous $\mathrm{T}$ cells cluster around postcapillary venules of the superficial dermal plexus, the main site of leucocyte extravasation in the skin. In this study, we identified the chemokine I-309/CCLl on cutaneous blood microvessels as well as epidermis associated Langerhans cells (LCs) and melanocytes in normal human skin (fig 5). ${ }^{43}$ CCLl was not detected on keratinocytes or dermal fibroblasts, two types of tissue cell that are well known to produce a variety of mostly inflammatory chemokines. ${ }^{14}$ Furthermore, the majority of $\mathrm{T}$ cells in healthy human skin expresses functional CCR8, the single receptor for CCL1, whereas other chemokine receptors were low or even absent (see fig 5). Also, lack of CCR7 and borderline expression of receptors for inflammatory chemokines indicate that memory $\mathrm{T}$ cells within healthy skin form a $\mathrm{T}$ cell subset that is different from $\mathrm{T}_{\mathrm{CM}}$ cells and $\mathrm{T}_{\mathrm{EM}}$ cells. CCR8+ $\mathrm{T}$ cells were not detected in other healthy peripheral tissues, including the gastrointestinal tract. Finally, CCR8+ $\mathrm{T}_{\mathrm{PS}}$ cells produced large amounts of the proinflammatory cytokines tumour necrosis factor $\alpha$ $(\mathrm{TNF} \alpha)$ and interferon $\gamma$ irrespective of CD4 or CD8 expression, whereas secretion of type 2 cytokines (IL-4, IL-5, IL-13) or elaboration of cytolytic functions were rarely observed. ${ }^{43}$ We concluded that cutaneous CCR8+ T cells represent the first example of a memory $\mathrm{T}$ cell subset that fulfils the criteria of $T_{P S}$ cells. The phenotypic characteristics suggest that skin $\mathrm{T}_{\mathrm{PS}}$ cells respond to local antigen challenges by contributing to the inflammatory cascade right at the site of pathogen entry. It remains to be determined whether activated skin $\mathrm{T}_{\mathrm{PS}}$ cells can also acquire LN-homing properties-that is, CCR7 expression, as observed during activation of peripheral blood $\alpha \beta$ T cells. ${ }^{14} 4142$

The identification of skin selective $\mathrm{T}_{\mathrm{PS}}$ cells suggests that additional $\mathrm{T}_{\mathrm{PS}}$ cells with homing preferences for alternative peripheral sites, such as healthy airways, lung, and the gastrointestinal and urogenital tracts, may exist. Detailed analysis of the expression of homoeostatic chemokines by the microvasculature feeding these sites may lead the way to understanding the trafficking preferences and function of peripheral immune surveillance T cells.

\section{ACKNOWLEDGEMENT}

We thank Dr Pius Loetscher for preparing fig 1.

\section{Authors' affiliations \\ B Moser, K Willimann, Theodor-Kocher Institute, University of Bern, Bern, Switzerland}

This work was supported in part by Swiss National Science Foundation grant 31-103687 and Bundesamt für Bildung und Wissenschaft grant $99.0471-5$

Correspondence to: B Moser, Theodor-Kocher Institute, University of Bern, Freiestrasse 1, CH-3012 Bern, Switzerland; bernhard.moser@tki. unibe.ch

\section{REFERENCES}

1 Baggiolini M, Dewald B, Moser B. Interleukin-8 and related chemotactic cytokines - CXC and CC chemokines. Adv Immunol 1994:55:97-179.

2 Baggiolini M, Dewald B, Moser B. Human chemokines: An update. Annu Rev Immunol 1997; 15:675-705.

3 Cytokine Family Database (dbCFC). http://cytokine.medic.kumamoto-u.ac.jp (accessed 21 May 2004). 
4 Murphy PM, Baggiolini M, Charo IF, Hebert CA, Horuk R, Matsushima K, et al. International union of pharmacology. XXII. Nomenclature for chemokine receptors. Pharmacol Rev 2000;52:145-76.

5 Murphy PM. International Union of Pharmacology. XXX. Update on chemokine receptor nomenclature. Pharmacol Rev 2002;54:227-9.

6 Zlotnik A, Yoshie O. Chemokines: a new classification system and their role in immunity. Immunity 2000;12:121-7.

7 Loetscher P, Moser B, Baggiolini M. Chemokines and their receptors in lymphocyte traffic and HIV infection. Adv Immunol 2000;74:127-80

8 Thelen M. Dancing to the tune of chemokines. Nat Immunol 2001;2:129-34.

9 Moser B, Loetscher M, Piali L, Loetscher P. Lymphocyte responses to chemokines. Intern Rev Immunol 1998; 16:323-44.

10 Lasagni L, Francalanci M, Annunziato F, Lazzeri E, Giannini S, Cosmi L, et al. An alternatively spliced variant of CXCR3 mediates the inhibition of endothelial cell growth induced by IP-10, Mig, and I-TAC, and acts as functional receptor for platelet factor 4. J Exp Med 2003;197:1537-49.

11 Nibbs RJ, Kriehuber E, Ponath PD, Parent D, Qin S, Campbell JD, et al. The beta-chemokine receptor D6 is expressed by lymphatic endothelium and a subset of vascular tumors. Am J Pathol 2001;158:867-77.

12 Hadley TJ, Peiper SC. From malaria to chemokine receptor: The emerging physiologic role of the Duffy blood group antigen. Blood 1997;89:3077-91.

13 D'Amico G, Frascaroli G, Bianchi G, Transidico P, Doni A, Vecchi A, et al. Uncoupling of inflammatory chemokine receptors by IL-10: generation of functional decoys. Nat Immunol 2000;1:387-91.

14 Moser B, Wolf M, Walz A, Loetscher P. Chemokines: multiple levels of leukocyte migration control. Trends Immunol 2004;25:75-84.

15 Loetscher P, Clark-Lewis I. Agonistic and antagonistic activities of chemokines. $J$ Leukoc Biol 2001:69:881-4.

16 Loetscher P, Pellegrino A, Gong JH, Mattioli I, Loetscher M, Bardi G, et al. The ligands of CXC chemokine receptor 3, I-TAC, Mig, and IP10, are natural antagonists for CCR3. J Biol Chem 2001 ;276:2986-91.

17 Ogilvie P, Bardi G, Clark-Lewis I, Baggiolini M, Uguccioni M. Eotaxin is a natural antagonist for CCR2 and an agonist for CCR5. Blood $2001 ; 97: 1920-4$

18 Ogilvie P, Paoletti S, Clark-Lewis I, Uguccioni M. Eotaxin-3 is a natural antagonist for CCR2 and exerts a repulsive effect on human monocytes. Blood 2003; 102:789-94.

19 Petkovic V, Moghini C, Paoletti S, Uguccioni M, Gerber BO. Eotaxin-3 (CCL26) is a natural antagonist for CCR1 and CCR5. J Biol Chem 2004.

20 Blanpain C, Migeotte I, Lee B, Vakili J, Doranz BJ, Govaerts C, et al. CCR5 binds multiple CC-chemokines: MCP-3 acts as a natural antagonist. Blood 1999;94:1899-905

21 Lindley I, Westwick J, Kunkel SL. Nomenclature announcement-the chemokines. Immunol Today 1993;14:24.

22 Moser B, Loetscher P. Lymphocyte traffic control by chemokines. Nat Immunol 2001;2:123-8.

23 Laudanna C, Kim JY, Constantin G, Butcher E. Rapid leukocyte integrin activation by chemokines. Immunol Rev 2002;186:37-46

24 Muller WA. Leukocyte-endothelial-cell interactions in leukocyte transmigration and the inflammatory response. Trends Immunol 2003;24:327-34.
25 Foxman EF, Campbell JJ, Butcher EC. Multistep navigation and the combinatorial control of leukocyte chemotaxis. J Cell Biol 1997; 139:1349-60

26 Matloubian M, Lo CG, Cinamon G, Lesneski MJ, Xu Y, Brinkmann V, et al. Lymphocyte egress from thymus and peripheral lymphoid organs is dependent on S1P receptor 1. Nature 2004;427:355-60.

27 Partida-Sanchez S, Goodrich S, Kusser K, Oppenheimer N, Randall TD, Lund FE. Regulation of dendritic cell trafficking by the ADP-ribosyl cyclase CD38: impact on the development of humoral immunity. Immunity 2004; 20:279-91.

28 Randolph GJ, Beaulieu S, Pope M, Sugawara I, Hoffman L, Steinman RM, et al. A physiologic function for p-glycoprotein (MDR-1) during the migration of dendritic cells from skin via afferent lymphatic vessels. Proc Natl Acad Sci U S A 1998:95:6924-9.

29 Saeki H, Moore AM, Brown MJ, Hwang ST. Secondary lymphoid-tissue chemokine (SLC) and CC chemokine receptor 7 (CCR7) participate in the emigration pathway of mature dendritic cells from the skin to regional lymph nodes. J Immunol 1999;162:2472-5.

30 Sprent J, Tough DF. T cell death and memory. Science 2001;293:245-8.

31 Kaech SM, Wherry EJ, Ahmed R. Effector and memory T-cell differentiation: implications for vaccine development. Nat Rev Immunol 2002;2:251-62.

32 Lanzavecchia A, Sallusto F. Progressive differentiation and selection of the fittest in the immune response. Nat Rev Immunol 2002;2:982-7.

33 Loetscher P, Moser B. Homing chemokines in rheumatoid arthritis. Arthritis Res 2002;4:233-6.

34 Moser B, Schaerli P, Loetscher P. CXCR5(+) T cells: follicular homing takes center stage in T-helper-cell responses. Trends Immunol 2002;23:250-4.

35 Proudfoot AE. Chemokine receptors: multifaceted therapeutic targets. Nat Rev Immunol 2002;2:106-15.

36 Onuffer JJ, Horuk R. Chemokines, chemokine receptors and small-molecule antagonists: recent developments. Trends Pharmacol Sci 2002;23:459-67.

37 Sallusto F, Lenig D, Förster R, Lipp M, Lanzavecchia A. Two subsets of memory $T$ lymphocytes with distinct homing potentials and effector functions. Nature 1999;401:708-12.

38 Schaerli P, Willimann K, Lang AB, Lipp M, Loetscher P, Moser B. CXC chemokine receptor 5 expression defines follicular homing $T$ cells with $B$ cell helper function. J Exp Med 2000;192:1553-62.

39 Breiffeld D, Ohl L, Kremmer E, Ellwart J, Sallusto F, Lipp M, et al. Follicular B helper T cells express CXC chemokine receptor 5, localize to B cell follicles, and support immunoglobulin production. J Exp Med 2000; 192:1545-52.

40 Schaerli $\mathbf{P}$, Loetscher P, Moser B. Cutting edge: induction of follicular homing precedes effector Th cell development. J Immunol 2001;167:6082-6.

41 Langenkamp A, Nagata K, Murphy K, Wu L, Lanzavecchia A, Sallusto F. Kinetics and expression patterns of chemokine receptors in human CD4+ T lymphocytes primed by myeloid or plasmacytoid dendritic cells. Eur J Immunol 2003:33:474-82

42 van Leeuwen EM, Gamadia LE, Baars PA, Remmerswaal EB, ten Berge IJ, van Lier RA. Proliferation requirements of cytomegalovirus-specific, effector-type human CD8+ T cells. J Immunol 2002; 169:5838-43.

43 Schaerli P, Ebert L, Willimann K, Blaser A, Roos RS, Loetscher P, et al. A skinselective homing mechanism for human immune surveillance $T$ cells. J Exp Med 2004;199:1265-75. 